in rats and mice. The human tumour xenografts will no doubt remain of considerable interest for immunologists, and the tumour kinetics may become simplified when the immunological contribution to cell loss is severely impaired. The system may be a useful tool for the study of the metabolism of therapeutic agents by human tumours in vivo; however, it is unwise to suppose the drug pharmacokinetics will necessarily be the same in man. What is needed now is a critical assessment of present knowledge of the system and more intensive study of the biological problems that it presents. Those who support this line of research should not be overimpressed by the lack of immediate progress towards producing the answer to the clinicians' cri de coeur, for biological science rarely advances along a direct path.

${ }^{1}$ Detre, S. I., and Gazet, J. C., British Fournal of Cancer, 1973, 29, 412. 2 Cobb, L. M., Cancer Research, 1974, 34, 958.

3 Castro, J. E., Nature, New Biology, 1972, 239, 83

4 Povlsen, C. O., and Rygaard, J., Acta Pathologica et Microbiologica Scandinavica, Section A, 1971, 79, 159 .

${ }^{5}$ Giovanella, B. C., et al., fournal of the National Cancer Institute, 1973, 50, 1051 .

- Geran, R. I., et al., Cancer Chemotherapy Reports, 1972, 3, 2.

7 Berenbaum, M. C., et al., British fournal of Cancer, 1974, 30, 13.

\section{Jugular Venous Pressure}

Traditionally the medical student is taught the importance of careful inspection of the jugular venous pressure and the jugular venous waveform. A final year student will know that a raised jugular venous pressure is a sign of congestive cardiac failure and that the extent of the rise is a measure of the severity of failure; he will recognize that "a" waves are absent from the jugular pulse in atrial fibrillation, that giant " $a$ " waves are present in severe pulmonary hypertension, pulmonary stenosis, and tricuspid stenosis, that cannon waves occur in complete heart block and somearrhythmias, and that one of the manifestations of tricuspid regurgitation is a large " $v$ " wave. But take the student to the bedside and all too often he is unable to demonstrate clinically his theoretical knowledge. It is at times a serious reflection on his teachers that basic questions as to the anatomical position of the external and internal jugular veins, the reference point for measurement of the jugular venous pressure, and the best positioning of the patient result in perplexity. However, it is well to remember that Paul Wood, ${ }^{1}$ who found it "hard to conceive of any physical sign that is more informative," stressed that diligent care and patience had to be exercised in examination of the neck veins; and that Lewis, ${ }^{2}$ recognizing the superiority of direct measurement of the jugular venous pressure, pointed out that much information could be obtained by "simple bedside tests that may be applied by any thoughtful and good observer." A clinical sign which is difficult to elicit is in danger of becoming obsolete through neglect, and this is especially likely if new techniques are at hand to supplant it. In these circumstances, it falls to the clinician to protect his art.

In a recent study of 39 seriously ill patients Davison and Cannon $^{3}$ compared the degree of accuracy achieved by measurement of the central venous pressure with an intrathoracic catheter proximal to the right ventricle with independent inspection of the jugular venous pulses by each investigator. Both the right and left internal and external jugular veins were inspected in end-inspiration and end-expiration-a possible total of 312 estimations. In fact 128 readings were obtained, of which 103 were external jugular vein pressures with only 25 internal jugular vein estimations. The correlation of these pressures with the central venous pressure was extremely poor; only $47 \%$ of the pooled observations were within $2 \mathrm{~cm}$ of the recorded value, and $90 \%$ agreement would have meant accepting a $4 \mathrm{~cm}$ error. On the basis of these results the authors conclude that the central venous pressure cannot reliably be estimated by inspection of the jugular veins and that if accurate measurement of the central venous pressure is required the placement of an intrathoracic venous catheter is unavoidable.

This study draws attention to the limitations of clinical measurement of the jugular venous pressure, but the clinical value of the jugular venous pressure (as distinct from the pulse waveform) is its elevation in cardiac failure; clinical evaluation of the jugular venous pressure in low output states is only of indirect value. Unfortunately, the actual measurements of the central venous pressure in this study were not given, but it seems that many were low, and this might account for some of the discrepancies. Direct measurement of the central venous pressure is undoubtedly more accurate than inspection of the jugular venous pressure, but as with all invasive techniques there are definite risks, ${ }^{4}$ and the clinician should ensure that he and his students are skilled in eliciting one of the most valuable signs in clinical medicine.

1 Wood, P., Diseases of the heart and circulation, 2nd edn. London, Eyre and Spottiswoode, 1956.

2 Lewis, T., British Medical fournal, 1930, 1, 849.

3 Davison, R., and Cannon, R., American Heart fournal, 1974, 87, 279

Rudge, C. J., Bewick, M., and McColl, I., British Medicalfournal, 1973, 3,23 .

\section{Screening for Hyperlipidaemia in Childhood}

Over half the men with familial hyperbetalipoproteinaemia develop ischaemic heart disease ${ }^{1}$ by the age of 50 . Heterozygotes may have overt heart disease in their teens; homozygotes may be affected in infancy, and seldom survive beyond 20-30 years. Disfiguring xanthomata, aortic stenosis, polyarthritis $^{2}$ and synovitis, are further manifestations.

Though experimental studies suggest that atherosclerosis may be partly reversible by diets modified in fat content, ${ }^{3}$ the most effective approach to the problem of ischaemic heart disease is likely to be preventive. ${ }^{4}$ The effect of the major risk factors $^{4}$ (hyperlipidaemia, hypertension, cigarette smoking) presumably depends on their duration as well as their intensity, so there is a growing belief that prevention should start in childhood or infancy. ${ }^{56}$ Attitudes to diet and smoking tend to be formed early in life.

Primary infantile hyperlipidaemia ${ }^{7}$ includes both hypercholesterolaemia due to excess low-density lipoprotein and hypertriglyceridaemia due to chylomicra or very-low density lipoprotein. Hyperlipidaemia may also be secondary, due to biliary obstruction, glycogenoses type I and II, diabetes, or idiopathic hypercalcaemia. While diagnosis necessarily requires laboratory investigation, xanthomata and retinal lipaemia are well worth seeking as diagnostic clues.

Neonatal screening for hyperlipidaemia has been attempted. ${ }^{9-14}$ Cord blood has the theoretical advantage over later sampling that the effect of diet cannot obscure the issue, ${ }^{11}$ and in 1971 Glueck et al. ${ }^{9}$ studied 1,800 samples in Cincinnati, measuring total cholesterol. They chose an upper limit of $100 \mathrm{mg} / 100 \mathrm{ml}$, about 2 standard deviations above the mean (statistically questionable as the distribution was skew). 
Of 65 neonates hypercholesterolaemic by this definition 14 had an affected parent. A year later Darmady et al.10 studied 302 neonates in London; 30 had cord cholesterol levels exceeding Glueck's limit. After one year 273 infants were re-examined and only 5 of the 30 were found still to be hypercholesterolaemic (by an arbitrary cutoff point of $240 \mathrm{mg} / 100 \mathrm{ml}$ ), and in only one was the hyperlipidaemia demonstrably familial. Surprisingly, cholesterol levels were higher in London than Cincinnati, so that strictly the $100 \mathrm{mg}$ / $100 \mathrm{ml}$ limit was inapplicable in London, but if a limit based on Darmady's mean plus 2 S.D. was used, most of the babies found to be hypercholesterolaemic at birth still had levels below $230 \mathrm{mg} / 100 \mathrm{ml}$ at one year. Darmady et al. concluded that the total cholesterol level in cord blood seemed without predictive value.

A one-year follow up of Glueck's hypercholesterolaemic neonates has now been reported. ${ }^{11}$ Using rigorous criteria, 8 neonates with hyperlipidaemia had evidence of dominant inheritance $(0.44 \%)$. Only 3 of the $8(0.17 \%)$ still had hypercholesterolaemia at one year. In 4 others normal levels were said to be due to their estimated diets being low in cholesterol, with high ratios of polyunsaturated to saturated fats preventing expression of the gene. Similar results were reported by Goldstein et al., ${ }^{12}$ who found levels of cholesterol, triglyceride, or both lipids exceeding 95th percentiles in 125 of 2,000 cord samples. Autosomal dominant hypercholesterolaemia was found in 5 , and 4 had combined hyperlipidaemia.

Monogenic inheritance appears to account for only a minority of cases of hyperlipidaemia in the neonatal period. The frequency of the autosomal dominant gene for familial hypercholesterolaemia is far lower than the frequency of adult hypercholesterolaemia. ${ }^{15}$ About $10 \%$ of Londoners ${ }^{16}$ have cholesterol levels exceeding $280 \mathrm{mg} / 100 \mathrm{ml}$; as the risk of ischaemic heart disease increases steeply ${ }^{17}$ when serum cholesterol exceeds $250 \mathrm{mg} / 100 \mathrm{ml}$, the figure of $10 \%$ may be an underestimate of the prevalence of hypercholesterolaemia. ${ }^{16}$

Cord blood levels of low-density lipoprotein (L.D.L.) may have greater diagnostic power than total cholesterol. ${ }^{13} 14$ In adult plasma, L.D.L. is the main transport protein for cholesterol. In familial hypercholesterolaemia L.D.L. levels are increased while high density lipoprotein (H.D.L.) may be subnormal. These reciprocal changes render total cholesterol a poor index of L.D.L. concentration, especially in infancy when H.D.L. carries as much as $50 \%$ of plasma cholesterol. ${ }^{13}$ In one study L.D.L. cholesterol in the cord blood was raised ( $>41 \mathrm{mg} / 100 \mathrm{ml}$ ) in 16 of 29 infants born to parents of whom one had familial hypercholesterolaemia. ${ }^{13}$ Nineteen infants were reinvestigated at 1-2 years; of 12 who had been abnormal as neonates 11 remained hypercholesterolaemic; and as none of the 7 who were normal at birth developed hyperlipidaemia the monogenic disorder may be fully expressed early in life. Greten et al..$^{14}$ have confirmed the value of L.D.L. assay in an extensive study. Measurement of L.D.L. by ultracentrifugation is available only in specialized centres, but simpler methods are becoming available. ${ }^{18} 19$

Familial hyperlipidaemia in heterozygotes is readily corrected; ${ }^{20}$ but at what age should treatment start in these apparently atherogenic disorders (raised L.D.L. and V.L.D.L. levels)? Strong and $\mathrm{McGill}^{21}$ noted that fatty streaks appeared in coronary arteries in the second decade in populations with both high and low incidences of heart disease. Though others disagree, ${ }^{22}$ they argued that some fatty streaks progress to raised atherosclerotic lesions. This progression apparently occurs in the third decade, particularly in communities prone to heart disease, and is seemingly due in part to known riskfactors; if so, efforts at prevention should be concentrated on this age-group. However, atherosclerosis evolves more rapidly in individuals with raised L.D.L. or V.L.D.L. levels, ${ }^{23}$ for whom early identification and treatment may prove beneficial. Extensive evaluation of cord blood lipoprotein assays is therefore justified for routine screening of babies born to hyperlipidaemic parents and to families with a history of early-onset heart disease.

1 Slack, J., Lancet, 1969, 2, 1380

2 Khachadurian, A. K., Arthritis and Rheumatism, 1968, :1, 385.

3 Armstrong, M. L., and Megan, M. B., Circulation Research, 1972, 30, 675.

4 Stamler, J., British Heart fournal, 1971, 33, suppl., 145.

5 Lloyd, J. K., and Wolff, O. H., Fournal of Atherosclerosis Research, 1969, 10,135 .

6 Mitchell, S. C., American fournal of Cardiology, 1973, 31, 539.

Fredrickson, D. S., and Breslow, J. L., Annual Review of Medicine, 1973, $24,315$.

${ }^{8}$ Stein, E. A., Mendelsohn, D., and Bersohn, I., South African Medical fournal, 1974, 48, 135.

9 Glueck, C. J., et al., Metabolism, 1971, 20, 597.

10 Darmady, J. M., Fosbrooke, A. S., and Lloyd, J. K., British Medical fournal, 1972, 1, 685 .

11 Tsang, R. C., Fallat, R. W., and Glueck, C. J., Pediatrics, 1974, 53, 458. 12 Goldstein, J. L., et al., Fournal of Clinical Investigation, 1973, 52, 35.

${ }^{3}$ Kwiterovitch, P. O., Levy, R. I., and Fredrickson, D. S., Lancet, 1973, 1, 118.

14 Greten, H., Wengeler, H., and Wagner, H., Nutrition and Metabolism, 1973, 15, 128

15 Carter, C. O., Slack, J., and Myant, N. B., Lancet, 1971, 1, 400.

16 Lewis, B., et al., Lancet, 1974, 1, 141.

Stamler, J., Berkson, D. M., and Lindberg, H. A., in The Pathogenesis of Atherosclerosis, ed. R. W. Wissler and J. C. Gree, p. 41. Baltimore, Williams and Wilkins, 1972 .

18 Burstein, M., and Scholnick, H. R., in Protides of the Biological Fluids, 19 th colloquium, ed. H. Peeters, p. 21. Oxford, Pergamon Press, 1971 Wilson, D. E., and Spiger, M. J., Fournal of Laboratory and Clinical Medicine, 1973, 82, 473 .

20 Tabaqchali, S., et al., British Medical fournal, 1974, 3, 377.

21 Strong, J. P., and McGill, H. C., Jnr., Fournal of Atherosclerosis Research, $1969,9,251$.

2 Mitchell, J. R. A., and Schwartz, C. J., Arterial Disease. Oxford, Blackwell Scientific Publications, 1965.

${ }^{23}$ Roberts, W. C., et al., American fournal of Cardiology, 1973, 31, 557.

\section{Imported Diseases}

One of the commonplaces of present-day medicine is the large increase in the number of patients seen in Britain and other European countries with so-called tropical diseases. The main reasons for this are self-evident-more people are travelling than ever before and the jet plane has enabled them to reach Europe during the incubation period of their illnesses; moreover, some foreign immigrants may bring unfamiliar illnesses with them. Unfortunately, many doctors have still not adjusted to the idea that an individual patient may be suffering from an imported disease. Part of the reason for a missed diagnosis may be a failure to ask Professor Brian Maegraith's celebrated question, Unde venis? Part may also be a lack of emphasis on the features of these illnesses in doctors' undergraduate and postgraduate training. This week the B.M.F. is starting a new short series of Medical Practice articles on imported diseases. The first, at p.397, by Dr. A. M. Geddes, is devoted to the problem of fever, and subsequent articles will deal with diarrhoea, worms, skin eruptions, and immunization for travel. 